\title{
POTENCIAL DE USO DA BIOMASSA FLORESTAL DA CAATINGA, SOB MANEJO SUSTENTÁVEL, PARA GERAÇÃO DE ENERGIA
}

\author{
POTENTIAL USE OF CAATINGA FOREST BIOMASS UNDER SUSTAINABLE MANAGEMENT \\ FOR ENERGY GENERATION
}

\author{
Martha Andreia Brand ${ }^{1}$
}

\begin{abstract}
RESUMO
O objetivo deste trabalho foi analisar o plano de manejo sustentável de uma área de caatinga, de forma a sugerir as melhores estratégias de tratamento da biomassa para geração de energia. $\mathrm{O}$ trabalho foi desenvolvido em um empreendimento privado, com área de 114.755 ha, na região sul do Piauí. A análise do plano de manejo, elaborado por Toniolo, Leal Junior e Campello (2005), foi feita pelo autor deste trabalho em três etapas. A primeira consistiu em um levantamento florístico e inventário florestal. O segundo estudo consistiu na quantificação e qualificação da biomassa florestal a ser destinada para geração de energia, incluindo a coleta de galhos no potencial total de biomassa. O terceiro estudo consistiu em realizar testes de estocagem da biomassa em campo e em pátio, para estimar a melhoria da qualidade da biomassa para geração de energia. Os resultados obtidos indicaram que a vegetação analisada apresenta: alta diversidade florística; muitos indivíduos por unidade de área; árvores de porte pequeno a médio; a maior parte dos indivíduos com diâmetro pequeno e alta produtividade de biomassa por unidade de área. Quanto à qualidade energética da biomassa da caatinga: o teor de umidade e o teor de cinzas das árvores recém-derrubadas foram baixos e o poder calorífico líquido foi alto. Quanto à estocagem: o corte das árvores na época de chuva e a sua manutenção em campo para a queda das folhas, por 10 dias, proporcionou um aumento significativo no teor de umidade da biomassa. Quinze dias de estocagem em pilhas, no pátio, foram suficientes para troncos e galhos de árvores da caatinga atingirem alta qualidade energética da madeira. As melhores estratégias de tratamento da biomassa consistiram em: realizar a colheita e coleta de toras e galhos manualmente, com o uso de motosserras. A colheita deve ser realizada de forma diferenciada nas estações de seca e chuva. $\mathrm{Na}$ estação seca, o máximo de material dos galhos deve ser retirado da área no momento da colheita das toras. No período das chuvas, os galhos não devem ser removidos do campo antes da queda das folhas, com posterior uso da estocagem em pilhas, em pátio, para a redução do teor de umidade. A massa específica; estrutura anatômica da madeira; morfológica das árvores e presença de cupinzeiros devem ser levados em consideração durante o planejamento de tratamento da biomassa para o uso na geração de energia, principalmente no dimensionamento dos picadores florestais e industriais. A estocagem das toras e dos galhos deve ser realizada separadamente, devido ao comportamento diferenciado da secagem da biomassa em função das dimensões e forma da mesma. A estocagem de toras e galhos de árvores da caatinga pode ser utilizada como ferramenta para o manejo da biomassa para geração de energia, de forma a melhorar a qualidade energética da madeira.
\end{abstract}

Palavras-chave: quantidade de biomassa; qualidade da biomassa; tratamento da biomassa; colheita.

\begin{abstract}
The aim of this study was to analyze the sustainable management plan of an area of Caatinga biome in order to suggest the best treatment strategies of biomass for energy generation. The study was conducted in a private enterprise, with an area of 114,755 ha in southern Piaui state. The management plan analysis, prepared by Toniolo, Leal Junior e Campello (2005), was made by the authors of this study in three steps.

1 Engenheira Florestal, Doutora, Professora do Departamento de Engenharia Florestal, Universidade do Estado de Santa Catarina, Av. Luiz de Camões, 2090, Conta Dinheiro, CEP 88520-000, Lages (SC), Brasil. martha.brand@udesc.br
\end{abstract}

Recebido para publicação em 23/07/2013 e aceito em 18/06/2015 
The first consisted of a floristic survey and forest inventory. The second study was the quantification and qualification of forest biomass to be allocated for energy generation, including the collection of branches in total biomass potential. The third study consisted of performing storage test of biomass in the field and in the forest and in an industrial yard, to estimate the improvement of the quality of biomass for energy generation. The results indicated that analyzed vegetation features: high floristic diversity, many individuals per unit area; small to medium trees; most individuals with small diameter and high biomass productivity per unit area. As for the energy quality of Caatinga biomass: the moisture content and ash content of newly felled trees were low and the net calorific value was high. As for storage: the cutting of trees during the rainy season and its field maintenance for the leave fall, for 10 days, it resulted in a significant increase in the moisture content of the biomass. Fifteen days of storage in piles in the yard were sufficient to trunks and branches of trees of Caatinga achieve high quality wood energy. The best biomass treatment strategies consisted of: performing harvesting and collecting logs and branches manually with the use of chain saws. The harvest should be done differently in the dry and rainy seasons. In the dry season, as much material from the branches should be removed from the area at the time of harvesting the logs. During the rainy season, the branches should not be removed from the field before the fall of leaves, with subsequent use of storage in piles, in the yard, to reduce the moisture content. The density; anatomical structure of wood; morphology of the trees and the presence of termites should be taken into account during treatment planning of biomass for the use in power generation, especially in the design of forest and industrial chippers. The storage of logs and branches should be performed separately due to the different behavior of drying the biomass depending on dimensions and shape thereof. The storage of logs and scrub of tree branches can be used as a tool for management of biomass for power generation in order to improve the energy of wood.

Keywords: biomass quantity; biomass quality; biomass treatment; harvesting.

\section{INTRODUÇÃO}

A vegetação de caatinga recobria, originalmente, quase todo o semiárido nordestino, equivalendo a pouco mais da metade dos 1,5 milhão de quilômetros quadrados da região (SAMPAIO, 1995). Atualmente, segundo o Sistema Nacional de Informações Florestais, a área de caatinga no Brasil, levantada pela Fundação Instituto Brasileiro de Geografia e Estatística (IBGE), em 2009, era de $844.453 \mathrm{~km}^{2}$, representando 9,92\% da área territorial do Brasil (BRASIL, 2012).

A caatinga é um mosaico de arbustos espinhosos e de florestas sazonalmente secas, com mais de 2.000 espécies de plantas vasculares, peixes, répteis, anfíbios, aves e mamíferos (LEAL et al., 2005). Rodal e Sampaio (2002) analisaram as implicações das diferentes descrições e delimitações de caatinga e identificaram três características básicas, na maioria dos escritos: (i) a vegetação que cobre uma área grande e mais ou menos contínua, no Nordeste do Brasil, submetida a um clima semiárido, bordejada por áreas de clima mais úmido; (ii) a vegetação desta área, com plantas que apresentam características relacionadas à adaptação da deficiência hídrica (caducifólia, herbáceas anuais, suculência, acúleos e espinhos, predominância de arbustos e árvores de pequeno porte, cobertura descontinua de copas, e (iii) a vegetação com algumas espécies endêmicas a esta área semiárida e com algumas espécies que ocorrem nesta área e em outras áreas secas mais distantes, mas não nas áreas circunvizinhas.

Porém, segundo Sampaio (2010), a conceituação de caatinga como uma vegetação exclusivamente regional deixa em aberto sua ligação com classificações mais gerais. Sem dúvida, a diversidade de fisionomias presentes no domínio das caatingas dificulta o enquadramento em qualquer tipologia e sempre haverá áreas de exceção.

A exploração da caatinga ocorre basicamente sob três formas: $(i)$ desmatamento legal, autorizado pelos órgãos competentes, para fins de uso alternativo do solo (agricultura, pastagem); (ii) manejo florestal sustentável, autorizado pelos órgãos competentes, para fins de produção madeireira, e (iii) desmatamento ilegal, para fins de uso alternativo do solo e produção madeireira (PAREYN, 2010).

Neste contexto, no Brasil, a mudança de uso do solo, ou seja, a conversão de terras florestais em terras agropecuárias é a causa principal do desmatamento. Acontece ainda a degradação florestal, que implica na redução dos estoques de biomassa das florestas e a diminuição de sua taxa de crescimento, gerando importantes emissões de $\mathrm{CO}_{2}$ e reduzindo sua capacidade para fixar $\mathrm{CO}_{2}$ atmosférico, tanto na 
biomassa viva quanto na biomassa morta e como carbono no solo (BENATTI, 2007).

Com relação à utilização da vegetação, as mais importantes categorias de uso de espécies da caatinga são para: construção (70,49\% das espécies), medicamentos (65,57\%) (SANTOS et al., 2008), e combustível $(54,91 \%)$ (FRANCELINO et al., 2003; FIGUEIRÔA et al., 2006; RAMOS et al., 2008; SANTOS et al., 2008; ALVAREZ et al., [s. d.]). Outra parte da vegetação é usada como pastagem nativa, com os animais consumindo a vegetação herbácea presente na época de chuvas e as folhas de árvores e de arbustos na estação seca (SCHACHT et al., 1989). Como combustível, a lenha pode ser utilizada como fonte energética para indústrias, comércio e domicílios, além de carvão vegetal (PAREYN, 2010).

Considerando apenas a demanda industrial e comercial, a produção de lenha e carvão gera aproximadamente 9.000 empregos diretos e outros 9.000 empregos indiretos, todos na zona rural, demonstrando o potencial de contribuição do setor florestal na redução da pobreza. Esses empregos incluem trabalhadores sem-terra (lenhadores), pequenos e médios produtores, transportadores, entre outros (PAREYN, 2010).

Porém, apesar do uso intensivo da caatinga como combustível, pouco se sabe sobre as quantidades de biomassas que são retiradas e recicladas nas partes das plantas utilizadas para este fim (SILVA; SAMPAIO, 2008). Assim, a gestão atual da terra na caatinga está se tornando insustentável, porque não existem protocolos adequados para refletir condições locais que assegurem a gestão sustentável dos recursos (FIGUEIRÔA et al., 2006).

Por outro lado, segundo Riegelhaupt et al., (2010), a caatinga é uma das florestas secas com melhores condições para se inserir no futuro mercado mundial de energéticos florestais por vários motivos, entre eles: o bioma esta localizado muito próximo do Atlântico Central, a curtas distâncias dos maiores polos mundiais consumidores de energéticos; a região da caatinga tem densidade populacional relativamente alta e boa infraestrutura viária, portuária e de comunicações; a sustentabilidade da produção está bem demonstrada e seus impactos ambientais são mínimos; $10 \%$ da área poderia estar disponível para manejo, podendo fornecer uma produção sustentável três a quatro vezes maior que a demanda atual, oferecendo assim um superavit considerável.

Além disso, é impossível pensar no desenvolvimento sustentável com base na energia fóssil que, por definição, é não renovável. É necessário iniciar uma transição energética para fontes renováveis de energia. Portanto, o manejo florestal da Caatinga tem muito a oferecer neste sentido (RIEGELHAUPT et al., 2010).

O Manejo Florestal, entendido como o conjunto de intervenções efetuadas em uma área florestal, visando à obtenção continuada de produtos e serviços da floresta, mantendo sua capacidade produtiva e a diversidade biológica, é uma atividade relativamente recente no bioma Caatinga, assim como sua investigação (GARIGLIO, 2010).

Segundo Riegelhaupt et al., (2010), o manejo florestal da Caatinga vem sendo questionado por diversos públicos no que diz respeito a sua sustentabilidade, e lamentavelmente confundido com o desmatamento puro e simples, provavelmente porque os tipos de corte aplicados na Caatinga, ao contrário dos utilizados nas florestas tropicais úmidas, são bastante intensivos, geralmente cortes rasos. Esta opinião "pouco informada" sobre os impactos do manejo na Caatinga omite duas considerações necessárias: $(i)$ cada tipo de vegetação tem características peculiares e (ii) uma técnica vantajosa em determinado tipo florestal pode não ter iguais valores ou impactos em outra floresta.

A Caatinga é um bioma florestal do semiárido característico de um clima marcado por fortes secas e queimadas recorrentes. Sob essas condições, as espécies arbóreas dominantes têm desenvolvido adaptações como: alta capacidade de regenerar por brotação de tocos e cepas; rápida resposta e alta taxa de crescimento em períodos úmidos; caducifólia e redução significativa do metabolismo em períodos secos (RIEGELHAUPT et al., 2010).

Essas características, já bem conhecidas, e os resultados de 25 anos de pesquisas e aplicação prática do manejo florestal da Caatinga demonstram que: o manejo tem viabilidade e sustentabilidade técnica além do esperado; as taxas de crescimento são altas, quando comparadas com outras florestas; a recuperação dos estoques ocorre em prazos relativamente curtos, principalmente devido à alta capacidade de regeneração e rápido crescimento inicial da rebrota (de tocos e raízes); a não utilização de maquinário pesado, de agrotóxicos e do fogo levam à boa conservação do solo; os grupos biológicos estudados apresentam níveis 
de diversidade praticamente iguais nas áreas manejadas e nas áreas conservadas, além do que a diversidade de habitat criada em áreas manejadas (talhões de idades distintas) permite ainda o aparecimento de novas espécies (RIEGELHAUPT et al., 2010).

Além disso, existem três grandes beneficiários do manejo florestal da Caatinga: (i) o produtor rural: por ter o manejo como uma alternativa produtiva na sua propriedade para gerar renda em base sustentável; (ii) o consumidor (indústria ou comercio): para obter a sua fonte de energia de forma legalizada e regularizada (abastecimento contínuo de origem conhecida); e (iii) o Estado: para exercer a gestão sustentável das florestas, gerando emprego e renda e legalizando a produção e o consumo de produtos florestais (PAREYN, 2010).

Finalmente, o manejo permite a sustentabilidade produtiva, evitando processos de degradação e reduzindo os riscos de desertificação, com impacto direto na viabilidade das propriedades rurais e manutenção do homem no campo, impedindo processos de pobreza rural e urbana (PAREYN, 2010).

Diante da crescente demanda global por energia renovável, a capacidade do manejo florestal da Caatinga para fornecer combustíveis lignocelulósicos e carvão vegetal com sustentabilidade, com mínimos investimentos, reduzidos efeitos nocivos para o ambiente e contribuindo para a conservação da biodiversidade, deve ser considerada como uma vantagem competitiva e uma sólida base para o desenvolvimento da Região Nordeste (RIEGELHAUPT et al., 2010).

No semiárido, o manejo florestal da vegetação nativa ("caatinga") surge como uma alternativa sustentável que alia a conservação dos recursos naturais com a geração de renda para as comunidades. Já existem disponíveis na região, sistemas de manejo florestal desenvolvidos e testados para garantir a produção sustentável de lenha, carvão e outros produtos madeireiros e não madeireiros, permitindo ainda a integração com a pecuária extensiva (SILVA et al., 2008).

Portanto, o objetivo deste trabalho foi analisar os estudos realizados para a elaboração do plano de manejo sustentável em uma área de caatinga, no sul do Piauí, de forma a sugerir as melhores estratégias de tratamento da biomassa para geração de energia.

\section{MATERIAIS E MÉTODOS}

\section{Descrição da área de estudo}

O trabalho foi desenvolvido em um empreendimento privado, denominado Condomínio Fazenda Chapada do Gurguéia, na região sul do Piauí. As terras do condomínio pertencem a dois municípios: Redenção do Gurguéia e Morro Cabeça no Tempo. As sedes destes municípios se localizam, respectivamente, a noroeste e a sudeste da sede da propriedade, que está contida entre as coordenadas geográficas dos

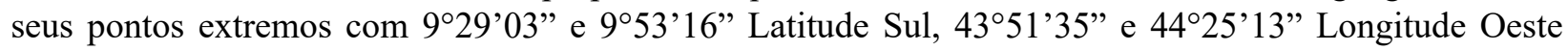
(TONIOLO et al., 2005) (Figura 1).

Segundo Toniolo, Leal Junior e Campello (2005), o empreendimento tem área total de 114.755 ha, está localizado no topo plano de uma chapada sedimentar arenítica, denominada "Serra Vermelha". A área do condomínio situa-se integralmente na Grande Unidade de Paisagem das Chapadas Intermediárias e na Unidade Geoambiental das Chapadas do Extremo Sul do Piauí (B2), segundo o Zoneamento Agroecológico do Nordeste do Brasil.

A região situa-se na transição de Tropical Semiárido para Tropical Subúmido Seco. A estação seca é do mês de maio a outubro e a chuvosa é de novembro a abril, sendo março o mês mais chuvoso, precipitação média anual de $850 \mathrm{~mm}$, beneficiando-se, ainda, durante a estação seca, por abundante orvalho e pelas "neblinas", devido à altitude local (TONIOLO et al., 2005).

As temperaturas máximas variam de $29,4^{\circ} \mathrm{C}$ em fevereiro a $36^{\circ} \mathrm{C}$ em setembro, com média máxima anual de $32,6^{\circ} \mathrm{C}$ e média mínima anual de $19,1^{\circ} \mathrm{C}$. As oscilações mensais mínimas são de $17,2^{\circ} \mathrm{C}$ em julho (menor) a $21,8^{\circ} \mathrm{C}$ em outubro (maior). Tais temperaturas são amenizadas pelos ventos que transportam umidade, contribuindo para oscilações das temperaturas à noite (TONIOLO et al., 2005).

A umidade do ar apresenta médias mensais de $43 \%$ em agosto (mais baixa) a $80 \%$ em janeiro (mais alta), com taxa média anual de $62,2 \%$. Os maiores valores da umidade relativa do ar estão concentrados entre dezembro a maio, com flutuações entre $64 \%$ e $70 \%$. No período de junho a outubro, observou-se uma 


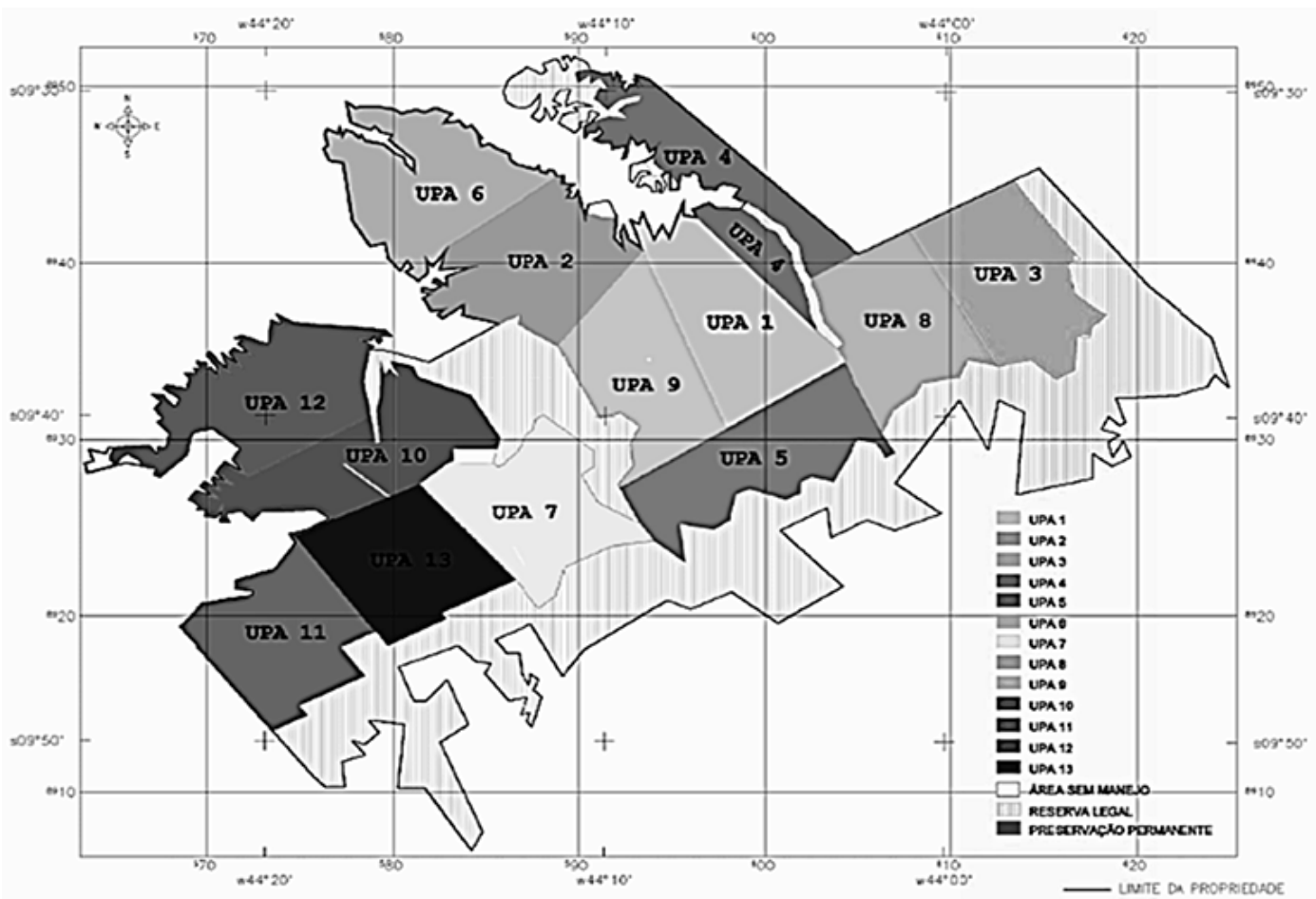

FIGURA 1: Área do projeto de Manejo Sustentável da Caatinga (Fonte: TONIOLO; LEAL JUNIOR; CAMPELLO, 2005).

FIGURE 1: Area of the project of Sustainable Management of Caatinga.

redução gradativa da umidade relativa do ar (TONIOLO et al., 2005).

A vegetação existente dentro do empreendimento pode ser denominada fitogeograficamente como Savana Estépica Florestada (caatinga), segundo a classificação do IBGE (1992), constituída por indivíduos micro e/ou nanofanerófitos, com média de $5 \mathrm{~m}$, excepcionalmente ultrapassando os $7 \mathrm{~m}$ de altura, mais ou menos densos, com grossos troncos e esgalhamento bastante ramificado em geral providos de espinhos ou acúleos, com total decidualidade na época desfavorável.

\section{Análise dos trabalhos realizados na vegetação quanto à quantificação e qualificação da biomassa, estratégias de colheita e tratamento da biomassa para geração de energia}

A análise do plano de manejo adotado na área, elaborado por Toniolo, Leal Junior e Campello (2005), foi feita pelos autores deste trabalho em três etapas. A primeira consistiu em um levantamento prévio para a confirmação do levantamento florístico e inventário florestal para geração de energia, realizados previamente por Toniolo, Leal Junior e Campello (2005) e pelo IBAMA para autorização do plano de manejo. O segundo estudo consistiu na quantificação e qualificação da biomassa florestal a ser destinada para geração de energia, incluindo a coleta de galhos no potencial total de biomassa. Os galhos não haviam sido incluídos nos estudos iniciais do plano de manejo. $O$ terceiro estudo consistiu em realizar testes de estocagem da biomassa em campo para estimar a melhoria da qualidade da biomassa para geração de energia. $\mathrm{O}$ estudo de estocagem não havia sido feito no plano de manejo, porém, foi realizado neste trabalho, pois surgiu a demanda de se avaliar a qualidade da biomassa para a geração de energia elétrica em um sistema termelétrico.

A partir destes estudos, os resultados apresentados e discutidos neste trabalho são relativos à apresentação das melhores estratégias de manejo desta vegetação e tratamento da biomassa oriunda dela para otimizar o seu uso para a geração de energia.

Assim, o levantamento florístico e o inventário florestal foram realizados em 2 parcelas de $20 \mathrm{~m}$ x $20 \mathrm{~m}$, utilizando-se a metodologia da proposta PNUD/FAO/IBAMA/BRA/87/007 (PROJETO PNUD/ 
FAO/IBAMA/BRA/87/007, 1992) para o semiárido. Para a caracterização da vegetação foram coletadas exsicatas e o inventário foi realizado a partir da medição das alturas e diâmetros na base, a uma altura de 30 $\mathrm{cm}$ do solo e DAP de todas as árvores com diâmetro maior que $2 \mathrm{~cm}$, nas parcelas. Todas as árvores foram derrubadas e traçadas com comprimento médio de $1 \mathrm{~m}$ para posterior determinação da massa em balança de campo, com precisão de $0,5 \mathrm{~kg}$.

A quantificação da biomassa foi realizada por meio da pesagem de todas as árvores contidas em dezessete parcelas com dimensões de $20 \times 20 \mathrm{~m}$. Nestas unidades amostrais foram incluídos os galhos na pesagem, além dos troncos. Foram calculados a quantidade de biomassa gerada por unidade de área (ha) e o potencial de geração de energia elétrica da biomassa na formação florestal. O potencial de geração de energia elétrica foi calculado a partir de dados previamente conhecidos, oriundos da experiência do uso da biomassa florestal em um sistema de cogeração em operação no sul do Brasil. Estes dados incluíram: (a) poder calorífico líquido médio da biomassa de $1.550 \mathrm{kcal} / \mathrm{kg}$ (valor da biomassa florestal utilizada na cogeradora); (b) a produção de biomassa, por unidade de área, obtida através dos resultados do trabalho; (c) um fator de conversão de 2,2 toneladas de biomassa para a geração de $1 \mathrm{MW} /$ hora de energia elétrica (este valor é baseado em valores de eficiência obtidos em uma cogeradora instalada na região sul do Brasil, que utiliza biomassa florestal para geração de energia elétrica); e (d) consumo médio de $200 \mathrm{KW} / \mathrm{hora} / \mathrm{mês}$ de energia elétrica de uma residência urbana.

Quanto à qualidade energética da biomassa da caatinga, a coleta da madeira de espécies pertencentes à formação florestal foi realizada em três momentos: entre 30 de maio e $1^{\circ}$ de junho de 2007 (final da época de chuva); entre 22 de outubro e $1^{\circ}$ de novembro de 2007 (final da época de secas na região) e entre 20 de janeiro e $1^{\circ}$ de fevereiro de 2008 (durante a época de chuvas).

Na primeira coleta foram analisadas oito espécies selecionadas com base na abundância de suas ocorrências na vegetação. A abundância foi determinada a partir de informações obtidas com mateiros da região e avaliação do trabalho realizado por Toniolo et al., (2005), que indicava que dentre as 66 espécies presentes na vegetação, estas oito estavam entre as 29 mais abundantes.

Na segunda atividade de campo foram demarcadas duas parcelas de $20 \times 20 \mathrm{~m}$, ao lado de parcelas permanentes do inventário florestal realizado por Toniolo et al., (2005), no qual todas as árvores foram cortadas, coletadas exsicatas para posterior confirmação da identificação das espécies e coletados discos em diferentes alturas do tronco e dos galhos de cada espécie componente da parcela. Desta forma, foi coletada a madeira de 28 espécies.

Em janeiro, foram demarcadas duas parcelas de 20 × 20 m, nas quais todas as árvores foram cortadas e destas retirados discos no tronco e galhos, para a composição de uma amostra única de cada parcela, contendo a mistura de todas as espécies componentes da vegetação.

Em todas as coletas, os discos foram acondicionados em recipientes plásticos fechados, identificados e enviados para o laboratório. As análises físicas e energéticas realizadas nas amostras foram: determinação do teor de umidade na base úmida, conforme ABNT NBR 14929 (2003c); massa específica básica, conforme ABNT NBR 11491 (2003a); teor de cinzas $\left(525^{\circ} \mathrm{C}\right)$, conforme ABNT NBR 13999 (2003b) e o poder calorífico superior e líquido em calorímetro, conforme a norma DIN 51900 (2000).

Quanto aos estudos de estocagem da biomassa em campo, foram coletadas amostras contendo galhos e troncos de várias espécies, e amostras de galhos e troncos separadamente em 5 parcelas de 20 × 20 $\mathrm{m}$. As amostras gerais foram avaliadas no estado recém-colhido e as amostras de galhos e toras após $15 \mathrm{e}$ 30 dias de estocagem em pilhas, no campo. As análises realizadas foram: teor de umidade na base úmida; teor de cinzas e poder calorífico.

\section{RESULTADOS E DISCUSSÃO}

\section{Quanto ao levantamento florístico, inventário e quantificação da biomassa realizados na área de estudo}

Foram identificadas 66 espécies arbóreas na formação florestal. Destas, 19 apresentaram maior abundância, representando $76 \%$ da diversidade. Entre elas, as com maior abundância foram: goiababrava (Eugenia sp), joão-mole (Pisonia sp), canela-de-velho (Cenostigma gardnerianum Tul.), marmela 
(Desmodium discolor Vogel), açoita-cavalo (Luehea sp), figueirinha-da-caatinga (não identificada) e paude-casca (não identificada). O estoque médio de lenha estimado foi de $150 \mathrm{~m}^{3} / \mathrm{ha}$ ou 106 a $160 \mathrm{t} /$ biomassa úmida/ha sem a inclusão de galhos. Incluindo-se os galhos na quantificação da biomassa os valores obtidos passaram a ser de 170 toneladas/ha. Com este último dado, a produção anual de biomassa permite a implantação de uma termelétrica com capacidade de geração de 53 MWh de energia elétrica.

O número médio de indivíduos por área foi de 4.205 árvores/ha e altura média de 5,6 m. A maior parte dos indivíduos $(51,87 \%)$ teve entre 02 a $05 \mathrm{~cm}$ de diâmetro, representando pequena contribuição para a produção de biomassa. Da biomassa útil para geração de energia, 46,99\% dos indivíduos teve entre 6 a 25 $\mathrm{cm}$ de diâmetro, representando $76,93 \%$ da biomassa disponível para geração de energia.

Analisando estes resultados é possível destacar como principais características da vegetação:

- Alta diversidade florística.

- Muitos indivíduos por unidade de área.

- Árvores de porte pequeno a médio.

- Maior parte dos indivíduos com diâmetro pequeno, sendo que a inclusão dos galhos na produção de biomassa aumenta ainda mais a quantidade de biomassa com pequeno diâmetro.

- Alta produtividade de biomassa por unidade de área.

Portanto, estas variáveis indicam a necessidade de tratamento especial da biomassa para geração de energia, relativo à coleta, transporte e preparação da biomassa, seja na forma direta de geração de energia térmica ou indireta, para geração de energia elétrica.

Com relação à diversidade florística, vale ressaltar que Tacher et al. (2002) propuseram que a utilização de um grande número de espécies implica um melhor uso ecológico desses recursos, funcionando como uma estratégia de conservação e reduzindo os riscos ecológicos para grupos de plantas específicas.

Por outro lado, o uso de diversas espécies implica maior variação na qualidade da madeira, em termos de massa específica básica, teor de umidade, teor de cinzas e, em menor importância, poder calorífico superior, quando se trata do uso energético da madeira.

Quanto à coleta ou colheita, o elevado número de indivíduos por unidade de área e a alta proporção de indivíduos de menor diâmetro, aliados à inclusão dos galhos na produção de biomassa requerem a realização de colheita manual, com o uso de motosserras. Além disso, os trabalhos de campo indicaram a necessidade da entrada prévia na área para limpeza de cipós e vegetação de menor porte que prejudicam as operações de derrubada e desgalhamento das árvores, além de comprometer a segurança operacional dos colaboradores.

O plano de manejo sustentável realizado por Toniolo et al., (2005) previa um ciclo de corte médio de 13 anos, com a manutenção de um número de árvores remanescentes em torno de 50 árvores/ha, para melhorar as condições de regeneração. Desta forma, a colheita deve ser realizada com o cuidado de se deixar árvores ainda com potencial para produção de sementes e crescimento, visto que as árvores mais velhas terão maiores diâmetros e, consequentemente, maior contribuição para produção de biomassa e, em contrapartida, menor contribuição para a regeneração da vegetação.

Apesar de não terem sido feitos estudos econômicos para a elaboração deste trabalho, a inclusão dos galhos aumenta o número de pessoas na atividade de colheita e coleta e exige o uso de equipamentos que permitam o transporte de galhos sem a perda de material durante esta etapa do tratamento da biomassa. Além disso, se forem incluídos equipamentos para a coleta dos galhos na área, estes não devem aumentar o teor de cinzas da biomassa pela coleta de terra, areia e pedras, juntamente com os galhos. Neste sentido, a coleta manual melhora a qualidade da biomassa, apesar de tornar a atividade mais demorada.

Como os estudos foram desenvolvidos tanto na estação seca, quanto chuvosa, os resultados obtidos indicam que o manejo deve ser diferente, para estas duas situações. Na estação seca, a pouca existência de folhas facilita a coleta e traçamento dos galhos grossos e finos, sendo que o máximo de material dos galhos deve ser retirado da área. Isso porque, na estiagem, os galhos estão sem folhas e com menor teor de umidade, podendo propiciar ou propagar incêndios, que são frequentes nesta época, e até dificultar a regeneração das espécies.

A maioria dos usuários domésticos de lenha da caatinga afirma que a lenha é preferencialmente colhida no verão ( $95 \%$ dos entrevistados), indicando que há um período durante o ano em que a extração de lenha é mais intensa. O principal motivo para este padrão sazonal, de acordo com os entrevistados, é que é 
mais fácil entrar e se movimentar na floresta, durante a estação seca (RAMOS et al., 2008).

Portanto, na estação seca, os galhos devem ser removidos juntamente com a colheita das toras. Os galhos se convertidos em cavacos logo após o seu corte, na época de seca, que é o mais viável para evitar incêndios e sua proliferação, terão maior teor de umidade, o que diminui seu poder calorífico. Assim, devese prever a necessidade de mistura (blendagem) dos diferentes materiais (galhos e toras), e realização de estocagem em pátios, para o maior ganho energético na planta de geração de energia.

No período seco, o manejo florestal apresenta-se especialmente como alternativa de trabalho e renda. A biomassa florestal na região Nordeste brasileira participa com aproximadamente $30 \%$ do balanço energético regional e não apresenta tendência clara de redução. Dentro deste contexto, existe, portanto, um mercado real para escoamento da produção florestal legalizada através de Planos de Manejo Florestal Sustentado (SILVA et al., 2008).

Os resultados obtidos por Figueirôa et al. (2006) fornecem valiosas informações sobre o manejo de caatinga. Eles mostram que, na colheita, a época do ano mais adequada para promover a regeneração é durante a estação seca. Portanto o regime de manejo permite a colheita e produção sustentável de madeira.

Em contrapartida, no período das chuvas, a coleta e traçamento dos galhos são dificultados pela presença de folhas. Este material não deve ser removido do campo antes da queda das folhas, sob pena da exportação dos nutrientes ali alocados e aumento do risco de erosão, devido às características do solo e maior intensidade de chuvas nesta época do ano.

Portanto, na estação de chuva, os galhos deverão permanecer no campo por determinado tempo até que as folhas sequem e caiam antes destes serem convertidos em cavacos, o que também facilitará a operação e eficiência dos picadores industriais ou florestais.

O clima sazonal tem pouco efeito sobre a sobrevivência das árvores, mas a época em que a colheita é realizada e o tipo de corte aplicado afetam a capacidade de germinação e sobrevivência de algumas espécies. A produção sustentável de madeira na caatinga é influenciada pelo sistema de manejo. Um único regime de manejo não pode ser uma boa abordagem para a gestão do ecossistema caatinga, porque há diferentes respostas das espécies aos diferentes tratamentos. Por exemplo, na estação chuvosa a decepa não é recomendada para algumas espécies, para a produção de madeira, mas poderia ser um valioso meio de controle de espécies, se este for o objetivo do manejo (FIGUEIRÔA et al., 2006).

\section{Quanto à qualidade energética da biomassa da caatinga}

O teor de umidade médio da madeira de árvores recém-cortadas foi entre $28 \%$ (época de seca) e $29 \%$ (época de chuva). A massa específica básica média variou de 0,716 a $0,735 \mathrm{~g} / \mathrm{cm}^{3}$. O teor de cinzas médio variou de 1,55 a $1,59 \%$. O poder calorífico superior médio variou de 4583 a $4701 \mathrm{kcal} / \mathrm{kg}$ e o poder calorífico líquido médio foi de $2952 \mathrm{kcal} / \mathrm{kg}$.

Portanto, a análise dos resultados indica que:

- O teor de umidade das árvores recém-derrubadas foi baixo, independentemente se a colheita foi feita na época de seca ou chuva, ideal para a geração de energia;

- A massa específica básica foi alta, gerando grande quantidade de massa por unidade de volume, representando alto rendimento energético das espécies avaliadas;

- O teor de cinzas foi baixo, produzindo pouco resíduos após o uso da madeira em sistemas de geração de energia;

- O poder calorífico líquido foi alto, em função do baixo teor de umidade da madeira;

- A qualidade da madeira das espécies de caatinga da região sul do Piauí é ótima para o uso energético

Com relação ao teor de umidade, a época de colheita não terá influência sobre a qualidade energética da madeira, o que é excelente e não é o que acontece em outras formações florestais. Brand e Muñiz (2010) analisando a influência da época de colheita de toras de Pinus taeda e Eucalyptus dunnii sobre a qualidade energética da biomassa constataram que a época de colheita das toras tinha influência direta sobre o teor de umidade da madeira recém-cortada.

Neste aspecto, a colheita pode ser realizada durante todo o ano, sem variação da qualidade energética da biomassa que entra na planta de geração de energia.

A alta massa específica das espécies componentes da vegetação; a presença de cristais de oxalato 
de cálcio na madeira devido à sua constituição anatômica; os sulcos profundos do caule de algumas espécies (exemplo: canela-de-velho (Cenostigma gardnerianum (Tul.)) e as árvores ocas que normalmente têm cupinzeiros em seu interior requerem projeto e dimensionamento adequado dos picadores florestais e industriais.

A massa específica básica alta está diretamente relacionada à maior dureza da madeira, refletindo em maior desgaste das ferramentas de corte e necessidade de uso de metais mais duros para sua fabricação. Da mesma forma, a presença de cristais e a terra e areia dos cupinzeiros contribuem para o desgaste prematuro das ferramentas e os sulcos dos troncos para menor uniformidade dos cavacos produzidos.

Em termos de forma e geometria das toras e galhos, estas características não causarão grandes transtornos para conversão em cavacos, uma vez que, como as toras e galhos são traçados em comprimentos que não ultrapassam $1,5 \mathrm{~m}$, a influência da tortuosidade na picagem é pequena.

Portanto, a massa específica, estrutura anatômica da madeira e morfológica das árvores, em função da variabilidade de espécies componentes da biomassa e presença de cupinzeiros são fatores importantes e que devem ser levados em consideração durante o planejamento de tratamento da biomassa para o uso na geração de energia. Isso porque o desgaste das ferramentas, incrustações e geração de resíduos minerais será maior quando comparado à biomassa de outra fonte, como de florestas plantadas, por exemplo.

\section{Quanto à estocagem da biomassa para a geração de energia}

O teor de umidade da biomassa recém-colhida variou de $39 \%$ com dois dias de permanência no campo após o corte a 79\% em biomassa cortada e deixada distribuída no campo por 10 dias, na época de chuva. Após estocagem em pilhas por 15 dias, os galhos ficaram com teor de umidade de $18 \%$ e as toras com $21 \%$, e poder calorífico líquido de $3432 \mathrm{kcal} / \mathrm{kg}$ e $3274 \mathrm{kcal} / \mathrm{kg}$, respectivamente. Após 30 dias, os galhos ficaram com $13 \%$ e as toras com $21 \%$ de umidade, e poder calorífico líquido de $3672 \mathrm{kcal} / \mathrm{kg}$ e 3240 $\mathrm{kcal} / \mathrm{kg}$, respectivamente.

Portanto, a análise dos resultados descritos acima indica que:

- O corte das árvores na época de chuva, na região sul do Piauí, e a manutenção da biomassa em campo para a queda das folhas, por 10 dias ou mais, proporcionou o aumento significativo do teor de umidade da biomassa, diminuindo sua qualidade energética.

- Os galhos tiveram melhor comportamento durante a estocagem, tendo melhoria mais significativa da qualidade energética.

- Quinze dias de estocagem foram suficientes para troncos e galhos de árvores da caatinga atingirem alta qualidade energética da madeira.

- A estocagem de toras e galhos de árvores da caatinga pode ser utilizada como ferramenta para o manejo da biomassa para geração de energia, de forma a melhorar a qualidade energética da madeira.

A estocagem de toras e galhos, após o corte, no campo, deve ser avaliada sob dois aspectos: (a) uso da estocagem em campo para contribuir com a ciclagem de nutrientes e controle da erosão e (b) variação do teor de umidade em função da estocagem em campo.

Inicialmente, foi recomendada, neste trabalho, a manutenção dos galhos no campo para a queda das folhas, para a promoção da ciclagem de nutrientes e melhorar o desempenho dos picadores. Por outro lado, a estocagem no campo promoveu o aumento significativo do teor de umidade da biomassa, o que diminui sua qualidade energética.

Porém, mesmo com o aumento da umidade, se for utilizada a estocagem em pilhas, em pátio, como ferramenta para a redução do teor de umidade, um curto período de tempo (15 dias) já é suficiente para a redução significativa da umidade. Desta forma, a manutenção da biomassa, principalmente de galhos no campo para a queda das folhas é recomendado na época de chuvas, com posterior uso da estocagem em pilhas, para a redução do teor de umidade.

Como o estudo comprovou, a estocagem das toras e dos galhos deve ser realizada separadamente, devido ao comportamento diferenciado da secagem da biomassa em função das dimensões e forma da mesma. 


\section{CONCLUSÕES}

Em função dos estudos realizados na área e no projeto de manejo sustentável, a colheita e a coleta de toras e galhos devem ser manuais, com o uso de motosserras. A colheita da biomassa deve ser realizada de forma diferenciada nas estações de seca e chuva. Na estação seca, o máximo de material dos galhos deve ser retirado da área no momento da colheita das toras. No período das chuvas, os galhos não devem ser removidos do campo antes da queda das folhas.

A época de colheita não teve influência sobre a qualidade energética da madeira. A massa específica, a estrutura anatômica da madeira e morfológica das árvores, em função da variabilidade de espécies componentes da biomassa, e a presença de cupinzeiros devem ser levados em consideração durante o planejamento de tratamento da biomassa para o uso na geração de energia, principalmente no dimensionamento dos picadores florestais e industriais.

A manutenção da biomassa, principalmente de galhos no campo para a queda das folhas é recomendado na época de chuvas, com posterior uso da estocagem em pilhas, em pátio aberto, para a redução do teor de umidade. A estocagem das toras e dos galhos deve ser realizada separadamente, devido ao comportamento diferenciado da secagem da biomassa em função das dimensões e forma da mesma. A estocagem de toras e galhos de árvores da caatinga pode ser utilizada como ferramenta para o manejo da biomassa para geração de energia, de forma a melhorar a qualidade energética da madeira.

\section{AGRADECIMENTOS}

A empresa Tractebel Energia S.A. pelo apoio financeiro através do projeto "Análise da potencialidade de uso de biomassa oriunda de florestas nativas sob manejo sustentável para a geração de energia" (ANEEL 0403-001/2007), ciclo 2006-2007, à empresa JB Carbon S.A pelo acesso à Fazenda Chapada do Gurguéia e à Universidade do Planalto Catarinense pelo apoio financeiro.

\section{REFERÊNCIAS}

AlVAREZ, I. A. et al. Potencial energético de área conservada de caatinga em Petrolina - PE. Disponível em: <http://www.alice.cnptia.embrapa.br/bitstream/doc/157736/1/OPB2315.pdf >. Acesso em: 10 maio 2012.

ASSOCIAÇÃO BRASILEIRA DE NORMAS TÉCNICAS. NBR 11491: Determinação da Densidade Básica. Rio de Janeiro, 2003a.

ASSOCIAÇÃO BRASILEIRA DE NORMAS TÉCNICAS. NBR 13999: Papel, cartão, pastas celulósicas e madeira - Determinação do resíduo (cinza) após a incineração a $525^{\circ} \mathrm{C}$. Rio de Janeiro, $2003 \mathrm{~b}$.

ASSOCIAÇÃO BRASILEIRA DE NORMAS TÉCNICAS. NBR 14929: Madeira - Determinação do teor de umidade de cavacos - Método por secagem em estufa. Rio de Janeiro, 2003c.

BENATTI, P. Mudanças climáticas: e tempo de agir. In: FÓRUM LATINO AMERICANO SOBRE MEIO AMBIENTE E DESENVOLVIMENTO - MUDANÇAS CLIMÁTICAS, 6., 2007, Belo Horizonte. Anais... Disponível em: $<\mathrm{http} / /$ www.ecolatina.com.br/pdf/anais/6_Forum_Latino_Americano/ PaulaBennati.pdf $>$. Acesso em: 20 ago. 2009.

BRAND, M. A.; MUÑIZ, G. I. B. DE. Influência da época de colheita da biomassa florestal sobre sua qualidade para a geração de energia. Scientia Forestalis, Piracicaba, v. 38, n. 88, p. 619-628, dez. 2010. BRASIL. Ministério do Meio Ambiente. Serviço florestal Brasileiro. [2012]. Disponível em: $<\mathrm{http}: / / \mathrm{www}$. florestal.gov.br/snif/recursos-florestais/os-biomas-e-suas-florestas>. Acesso em: 10/05/2012.

DEUTSCHES INSTITUT FÜR NORMUNG e. V. DIN 51900: Determining the gross calorific value of solid and liquid fuels using the bomb calorimeter, and calculation of net calorific value. Berlim, 2000.

FIGUEIRÔA, J. M. et al. Effects of cutting regimes in the dry and wet season on survival and sprouting of woody species from the semi-arid caatinga of northeast Brazil. Forest Ecology and Management, Amsterdam, v. 229, p. 294-303, 2006.

FRANCELINO, M. R. et al. Contribuição da caatinga na sustentabilidade de projetos de assentamentos no sertão Norte-Rio-Grandense. Árvore, Viçosa, MG, v. 27, n. 1, p. 79 - 86, 2003. 
GARIGLIO, M. A. A Rede de manejo florestal da caatinga. In: et al. (Org.). Uso sustentável e conservação dos recursos florestais da caatinga. Brasília: Serviço Florestal Brasileiro, 2010. p. 199-204. IBGE. Manual técnico de Vegetação Brasileira. Rio de Janeiro: IBGE, 1992.

LEAL, I. R. et al. Mudando o curso da conservação da biodiversidade na Caatinga do Nordeste do Brasil. Megadiversidade, Belo Horizonte, v. 1, n. 1, 2005.

PAREYN, F. G. C. Os recursos florestais nativos e a sua gestão no estado de Pernambuco - o papel do manejo florestal sustentável. In: GARIGLIO, M. A. et al. (Org.). Uso sustentável e conservação dos recursos florestais da caatinga. Brasília: Serviço Florestal Brasileiro, 2010. p. 99-112.

PROJETO PNUD/FAO/IBAMA/BRA/87/007. Plano de manejo florestal para a região do Seridó do Rio Grande do Norte. Natal: Ministério do Meio Ambiente, 1992.

RAMOS, M. A. et al. Use and knowledge of fuelwood in an area of Caatinga vegetation in NE Brazil. Biomass and Bioenergy, Oxford, v. 32, p. 510-517, 2008.

RIEGELHAUPT, E.; PAREYN, F. G. C.; BACALINI, P. O manejo florestal na caatinga: resultados da experimentação. In: GARIGLIO, M. A. et al. (Org.). Uso sustentável e conservação dos recursos florestais da caatinga. Brasília: Serviço Florestal Brasileiro, 2010. p. 199-204.

RIEGELHAUPT, E. M.; PAREYN, F. G. C.; GARIGLIO, M. A. O manejo florestal como ferramenta para o uso sustentável e conservação da caatinga. In: GARIGLIO, M. A. et al. (Org.). Uso sustentável e conservação dos recursos florestais da caatinga. Brasília: Serviço Florestal Brasileiro, 2010. p. 349-367. RODAL, M. J. N.; SAMPAIO, E. V. S. B. A vegetação do bioma caatinga. In: SAMPAIO, E. V. S. B. et al. (Ed.). Vegetação e flora da caatinga. Recife: PNE/CNIP, 2002. p. 11-24.

SAMPAIO, E. V. S. B. Caracterização do bioma caatinga - características e potencialidades. In: GARIGLIO, M. A. et al. (Org.). Uso sustentável e conservação dos recursos florestais da caatinga. Brasília: Serviço Florestal Brasileiro, 2010. p. 29-42.

SAMPAIO, E. V. S. B. Overview of the Brazilian Caatinga. In: BULLOCK, S. H.; MOONEY, H. A.; MEDINA, E. (Ed.). Seasonally dry tropical forests. Cambridge: Cambridge University Press, 1995. p. 35-63.

SANTOS, J. P.; ARAÚJO, E. L.; ALBUQUERQUE, U. P. Richness and distribution of useful woody plants in the semi-arid region of northeastern Brazil. Journal of Arid Environments, London, v. 72, p. 652-663, 2008.

SCHACHT, W. H. et al. Response of caatinga vegetation to decreasing levels of canopy cover. Pesquisa Agropecuária Brasileira, Brasília, v. 24, n. 11, p. 1421-1426, 1989.

SILVA, G. C.; SAMPAIO, E. V. S. B. Biomassas de partes aéreas em plantas da caatinga. Árvore, Viçosa, MG, v. 32, n. 3, p. 567-575, 2008.

SILVA, J. P. F.; SOARES, D. G.; PAREYN, F. G. C. Manejo Florestal da Caatinga: uma alternativa de desenvolvimento sustentável em projetos de assentamentos rurais do semi-árido em Pernambuco. In: BRASIL. Ministério do Meio Ambiente. Estatística Florestal da Caatinga. Brasília: MMA, 2008. v. 1, p. 6-17.

TACHER S. I. L. et al. Caracterización del uso tradicional de la flora espontânea en la comunidad Lacandona da Lacanha, Chiapas, México. Interciência, Caracas, n. 27, p. 512-520, 2002.

TONIOLO, E. R.; LEAL JUNIOR, G., CAMPELlO, R. C. B. Plano de manejo florestal integrado sustentável - Projeto Energia Verde. Relatório técnico. Piauí: Redenção do Gurguéia, 2005. 66 p. 